\title{
Research on the Development Strategy of Internet + Sports Tourism Industry Base on the SWOT Analysis
}

\author{
Cheng Li * \\ Tourism College of Zhejiang China, Hangzhou China, 311231 \\ 1162239621@QQ.COM
}

Keywords: Internet + Sports tourism; SWOT analysis; Industrial convergence; Development strategy

Abstract: Using the methods of literature induction, content analysis, field examination and regional contrast, this paper makes a perspective of the development of Internet + sports tourism industry from the perspective of SWOT, which shows the inevitable trend of the integration of Internet + sports tourism industry. It has the advantages of rich resources and strong integration, but the market development is difficult. The disadvantage of the lack of professional talents, online sports tourism market trading scale growth opportunities, as well as fierce market competition and external risk factors more threats. It has put forward the optimized development strategy of the Internet + sports tourism industry, attach importance to industrial services and improves service quality; combined with industrial intelligence, create and optimize the sharing platform of the network service industry; build a community network platform which integrates tourism, sports, sports and leisure in one, and improve the quality of the whole people's sports; guided by the government's policies. Also, we should establish a compound talent training mechanism and create an Internet + regulatory platform, with a view to promoting the integration of the Internet + sports + tourism industry.

\section{Introduction}

On March 5, 2018, Premier Li Ke-qiang put forward in his report on the work of the government at the first meeting of the 13th National People's Congress: "Develop and expand new momentum. We should enlarge and strengthen the emerging industrial clusters, implement the action of big data development, strengthen the research and application of the new generation of artificial intelligence, and promote "Internet +" in many fields such as health care, pension, education, culture, sports and so on [1]. In October 21, 2014, the State Council issued the "accelerating the development of sports industry". Some opinions on sports consumption put forward that China's sports industry should reach the target of 5 trillion by 2025 [2]. In August 2018, Zhejiang Tourism Bureau and Zhejiang Sports Bureau have mentioned in their Opinions on Developing Sports Tourism: Sports tourism is a new industrial form of deep integration of tourism industry and sports industry. It takes sports as the core and takes on-site watching, participating in experience and visiting as the main forms to meet the needs 
of health. Recreation, tourism and leisure for the purpose of providing the public with related products and services of a series of economic activities, involving fitness and leisure, competition performance, equipment manufacturing, facilities construction and other forms of business, which in order to speed up the development of sports tourism industry and promote sports tourism consumption [3].

In the era of Internet plus, how to promote the development of sports tourism industry and choose the corresponding development strategy, give full play to the relevance and radiation of sports industry, has become a problem to be solved urgently in the current industry.

\section{SWOT analysis of Internet + sports tourism}

SWOT analysis, also known as situation analysis, is a strategic analysis method in the field of management. The four letters of SWOT stand for Strength, Weakness, Opportunity, and Threat. Using SWOT analysis method to analyze the internal advantages, disadvantages and external opportunities and threats of the Internet + sports tourism industry, it can effectively identify its internal and external factors, which is of great significance for the development and research of sports tourism industry in China's Internet plus era.

\subsection{Advantage Analysis}

China has a vast territory with a long history and rich natural and geographical resources, which provides a guarantee for the development of the Internet + sports tourism industry. Sports tourism projects derived from the Internet + sports tourism industry include sports and sports events such as sports competitions, stadiums and so on. Besides, with the natural conditions of geographical location, our country also has many distinctive sports participation tourism projects, such as ice and snow sports in the northeast and mountain sports in the West. Water sports in coastal cities. Using the Internet platform for sports tourism integration marketing model, can effectively improve the popularity of sports tourism resources, establish a convenient network marketing platform for optimizing the service model of sports tourism industry, improve the layout of sports tourism is of great significance. For example, Ali Travel APP launched the Sports Tourism Exclusive Channel, which uses the O2 O (Online to Offline) business marketing model, including fishing, football, cycling and other sports tourism projects, providing a series of hotel, catering and other tourism elements, while building a payment platform and feedback zone, for tourists to bring great Convenience. The combination of the two not only promotes the development of the sports tourism industry's integration and innovation mechanism, but also promotes the transformation of the sports tourism industrial structure, and guides the sports brigade. Tourism consumption and improving the layout of sports tourism industry are of great significance.

\subsection{Disadvantage Analysis}

In the long run, the overall planning and strategic layout, the micro aspect of service quality and user experience have not yet been standardized, resulting in a smaller market scale and difficulty. Expand the diversified development mode. At present, the Internet + sports tourism industry provides more service products, but it has not yet formed a perfect scale, nor has it standardized the factors such as price positioning, market demand and regional differences. As far as online is concerned, the price of products and services provided by the Internet + sports tourism industry is much higher than that of conventional tourism products. The Internet + sports tourism industry is difficult to achieve balanced development in terms of profit mode and user demand. Its market development is difficult, and there are many problems in price positioning and resource integration, which need a long time to develop 
and improve. In addition, China's sports tourism industry started late, the development and management of sports tourism is extremely lack of talent, so to a large extent restricted the development and utilization of sports tourism resources, affecting the development of sports tourism industry. [5] It is difficult to meet the development needs of sports tourism industry. Under the strategic drive of "Internet +", the combination of sports tourism industry and the Internet has posed a more severe challenge to the cultivation of talents, especially the "Internet + sports + tourism" compound talents.

\subsection{Opportunity Analysis}

With the enhancement of China's comprehensive national strength and the hosting of a number of international sports events, the status of sports industry in China has been getting higher and higher, and gradually developed into an important force to promote China's economic transformation and upgrading, and enhance the soft power of sports culture. Therefore, it has also been increasingly supported and valued by the state, and has obtained a series of policies supported and being protection. Ali Sports + Ali Travel, Caesar Travel, Tencent Sports, Wanda, Tongcheng Travel Company and other large companies with the help of the Internet platform, the use of online or offline payment for tourists to provide transport, accommodation, tickets and other tourism elements of comprehensive information retrieval, consultation and booking services to form a benefit mechanism and Market operation, strategic cooperation, etc. [6].

\subsection{External Risk Analysis}

As a modern sports tourism industry, the integration with the Internet is an inevitable trend. Its development mode is also gradually evolving from the traditional OTA mode to the O2O mode (that is, using the "Internet +" mode, with the help of online platform for resource purchase, while providing users with offline sports tourism services, allowing users to enter online. However, there are many risks in this new marketing method. The growth of tourist volume will exert tremendous pressure on the environment, resources and equipment of the sports tourism industry. Under the line, the overall management level and service quality are not high, and tourists' seasonality is greater. All these factors are external risks of the development of Internet + sports tourism industry. Therefore, in order to realize the benign combination of the Internet and sports tourism industry, it is necessary to take the tourist demand as the guide and adopt a variety of preventive measures to avoid external risk factors.

\section{Internet + sports tourism industry development strategy}

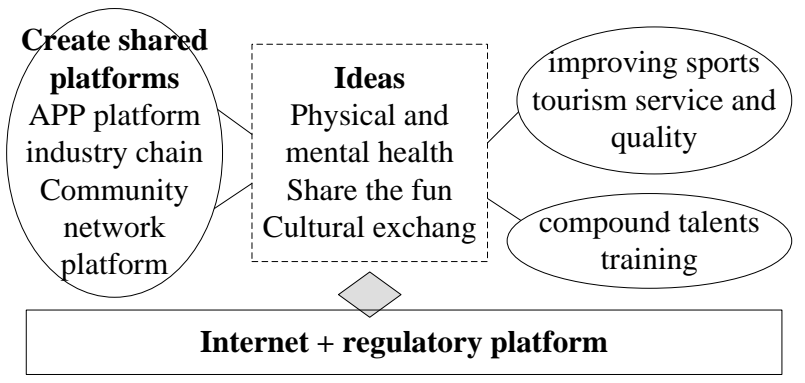

Figure. 1 Schematic diagram of Internet + sports tourism development strategy

The integration of Internet + sports tourism, with the support of the new generation of information technology, such as mobile Internet, cloud computing and big data, will provide technical support and development driving force for the sports tourism industry. This paper will elaborate on the following 
four aspects: improving sports tourism service and quality, creating shared platform, training Internet and sports tourism compound talents, and establishing internet + regulatory platform. Its development strategy is shown in Fig. 1.

\subsection{Improve the Service and Quality of Sports Tourism Industry}

Speeding up the development of service industry and increasing the proportion of service industry is the only way to accelerate the optimization of economic structure and the transformation of economic growth path. Sports service industry is an important part of China's service industry, is the essence and core of the sports industry, close to the people's livelihood, serve the masses of sports fitness, and meet the needs of improving the quality of life of the masses. People in sports and tourism activities, the basic idea is nothing more than to let themselves be happy, release pressure, let their physical and mental health, to share the fun of sports, in sports tourism with people and society to contact and exchange, to cultural people, scenery, heart feeling. The main task of sports tourism service should be to vigorously cultivate fitness and leisure, competitive performance, intermediary training and venue services. Under the guidance of relevant government policies, the government should encourage the development of potential sports tourism, sports media, venue operations and other forms of business, so that major companies or enterprise platforms should pay attention to their corporate image, as the body. Sports tourism provides the best service, guarantees the quality of service, enhances the pleasure and aftertaste brought by sports competition, performance competition and sports tourism, and better disseminates the brand effect of the enterprise itself.

\subsection{Create Internet + sports tourism industry sharing platform}

Strengthening the construction of the Internet + sports tourism industry platform can enhance user attractiveness, enhance user stickiness and loyalty, and also improve the professional segmentation of network passages, and improve the production and marketing efficiency of sports goods and services [7].

1) Create "Internet + sports tourism" sharing mobile platforms. The characteristics of the platform business model in the mobile Internet era are to use the mass relationship to establish the possibility of unlimited value-added and achieve a certain network effect. For example, Li Ning's intelligent running shoes, open offline experience, online consumption of the $\mathrm{O} 2 \mathrm{O}$ business model, completely meet consumer demand, to find a win the favor of market consumers operating mode. Therefore, the Internet + sports industry platform can timely understand and grasp customer demand information, and make the existing sports products and service modes innovative accordingly.

2) Expand the "Internet + sports tourism industry" platform industry chain. The platform of "Internet + sports tourism industry" enriches the carrier of "Internet + sports tourism industry" by means of sports tourism activities, sports sales, sports training, sports tourism, fitness and leisure, sports betting, sports tourism food promotion and so on. Add user sticky purpose. We should cultivate user groups, meet the diversified needs of users, and increase the stability of users through online and offline sports sales, sports training, sports tourism, leisure fitness and other specific forms, and further expand the Internet + Sports tourism industry.

3) Build a community network platform. Data sharing, nurturing new user groups, and stimulating the interaction among multi-groups of effective incentive platforms for the diversified development of sports tourism will be new initiatives to innovate the profit model of sports industry [8]. The Internet + sports industry community builds a mobile social platform through networking and information technology, providing comprehensive information services in various fields such as sports events, sports tourism, sports film and television media, health services, etc., while developing 
e-commerce activities with information platform to meet the needs of users.

\subsection{Speed up Internet + Sports + Tourism Compound Talents Training}

Sports tourism talents are the key factors of sports tourism resources and market development, but the current situation of sports tourism talents in China has greatly restricted the pace of their development. In August 2018, Zhejiang Tourism Bureau and Zhejiang Sports Bureau also mentioned the establishment of personnel training system in the "Opinions on the implementation of vigorous development of sports tourism". We should vigorously develop sports tourism education, support qualified tourism colleges and sports colleges to set up sports tourism-related majors, add sports tourism direction to tourism management majors or add corresponding professional courses, and speed up the training of sports tourism management personnel, professional and technical personnel and service skills. We should strengthen the training of sports tourism practitioners and constantly improve their professional skills and service levels. Sports tourism enterprises should be encouraged to cooperate with sports and tourism institutions to set up a practical training base for sports tourism. The contents of sports tourism should be included in the training system of tour guides. Strengthen the theoretical and practical research on the development of sports tourism industry, encourage the establishment of sports tourism expert pool and high-skilled talent pool, guide colleges and research institutions to provide intellectual support for sports tourism [3]. Therefore, colleges and universities should set up corresponding sports tourism specialty according to different regions and different humanities environment, arrange professional teaching plan rationally, so as to form a complete and systematic knowledge system for sports tourism specialty, so as to meet the social needs, so that tourism talents and sports talents have professional sports tourism knowledge industry background. In order to improve the service level of local and national sports tourism industry and promote the rapid development of sports tourism industry, high-quality talents who both understand sports and tourism can improve the service level of local and national sports tourism industry.

\subsection{Establish Internet + Regulatory Platform}

The integration and development of Internet + sports tourism provides people with extremely convenient travel trips, but also faces the test of network integrity (9). The establishment of the Internet + regulatory platform is to solve the problem of sports tourism products in the marketing process of network integrity, and improve the trust of tourists. We need to establish a regulatory platform for Internet businesses to ensure the authenticity of sports tourism projects provided by businessmen by verifying the information of offline businessmen, so as to supervise the business behavior of businessmen, establish a complaint feedback mechanism, according to the opinions and problems put forward by tourists to be solved in a timely manner, and effectively safeguard the interests of tourists. Because of the danger of sports tourism projects, we require businesses to provide the necessary security to minimize the harm caused by sports tourism. The establishment of Internet supervision platform requires the operators of sports tourism projects to provide quality sports tourism project services and follow-up security services to ensure the satisfaction and pleasure of sports tourists.

\section{Conclusions}

The Internet + sports tourism industry has good prospects for development and has strategic significance for promoting the development of sports tourism in China. Therefore, sports tourism resources should make full use of national policies to support vigorously, integrate with the Internet +, 
strengthen the development of the market, strengthen the integration of sports tourism projects and network service platforms, enhance their core competitiveness, establish a safety guarantee system, and minimize the external risk grade. The government should increase guidance and establish a training mechanism for compound talents, providing a powerful guarantee for the development of the Internet + sports tourism industry. All in all, the Internet + sports tourism industry is facing a good environment for internal and external development. The integration of the two is an important way to achieve the upgrading of China's sports tourism industry, and will become an important force to promote the development of China's sports tourism industry network and modernization.

\section{Acknowledgements}

This work was supported by the teaching reform of Tourism College of Zhejiang China in 2016 (Project No: 2016YB15) and the scientific research project of education department of Zhejiang Province in 2013 (Project No: zgt201330)

\section{References}

[1] Li Ke-qiang. Report on the work of the government (written record)[EB/OL](. 2018-03-05)[2018-03-08]. http://www.gov.cn/guowuyuan/2018-03/05/content_5271083.htm.

[2] The state council. Opinions of the State Council on accelerating the development of sports industry and promoting sports consumption[EB/OL]. (2014-10-20) [2018-03-09]. http://sports.people.com.cn/n/2014/1020/c22155-25868474.html. Zhejiang Tourism Bureau, Zhejiang Sports Bureau.

[3] Suggestions on vigorously developing sports tourism [EB/OL] (2018-08-08). http://www.jhsports.gov.cn/02/201808/t20180808_2590504_1.html

[4] Zhang Youfu, Guo Wei, Huang Xiaoxiao. SWOT analysis of developing outdoor sports tourism and leisure industry in Guizhou [J]. Journal of Nanjing Sport Institute: Social Science Edition, 2013 (3): 66 - 70.

[5] Shan Fengxia. Comparison of the Training Models of Sports Tourism Professionals between China and Britain and the United States [J]. Journal of Physical Education, 2015 (4): 66-70.

[6] Yi Guan think tank. China Online Travel Annual Comprehensive Analysis Report 2007 [EB/OL]. http://www.pinchain.com/article/127301, 2017.07.24.

[7] Xia yuan-qing. Integration and Innovation: the ecological trend of sports industry under the background of "Internet +" [J]. Journal of Nanjing Sport Institute, 2016, 30 (3): 70.

[8] Zhang Sen-mu. Internet + sports industry development strategy research [J]. Sports culture guide, 2016 (3): 121 124.

[9] Sun Jian-peng. Research on the market order management of sports industry under the construction of "Internet + sports" [J]. Hubei sports science and technology, 2017, 36 (1): 18-20, 23.

[10] CHEN Li-chun. Sports industry development under the "sharing economy" mode [J]. Journal of Shandong Sport University, 2017, 33(3):9-15. 